\title{
Challenges of the Development of Intelligent Transportation to the Transport Law System
}

\author{
Zhang Zhuxin, Zheng Xiang \\ Law school, Beijing Jiaotong University
}

\begin{abstract}
:
Intelligent transportation plays an increasingly important role in the transportation in China, and the new social relations produced by the emerging field of intelligent transportation has not been included into the research category by the current traffic laws, specific including the lack of a clear legal system of intelligent transportation industry technology support policy; the lack of interconnectivity safeguard legal system in intelligent transport legal system; the lack of related legal norms in Intelligent traffic information management system; and the lack of unified coordination mechanism in intelligent traffic emergency system. Therefore, intelligent transportation should be provided for the basic legal system to clear intelligent transportation industry policy, making various connectivity transportation regulations, to set up the transportation information management system, and establish the communication mechanism between traffic management agencies and other emergency agencies.
\end{abstract}

Keywords: Intelligent transportation; traffic laws; interconnectivity; informatization

\section{Introduction}

Intelligent traffic plays an increasingly important role in the transportation industry of China, it provides better services for people to travel, improves the operation efficiency of the transport system and increases of the security guarantee of the system. However, the new social relations produced by the emerging field of intelligent transportation has not been included into the research category by the current traffic laws, and the legal challenge posed by this new technology has not been given corresponding responses. So the thesis tries to analyze the demand for law in the intelligent transportation economic relations, and give some suggestion about how to improve the related legal system.

\section{Overview of Intelligent Transportation}

Intelligent transportation system (Intelligence Transport System, ITS for short) refers to the effective integrated application of the advanced information technology, data communication technology, electronic sensing technology, electronic control and computer processing technology to the entire transportation management system. ${ }^{1]}$ By the closer cooperation of people, vehicles and the road, intelligent transportation system improves the transportation efficiency, reduce traffic congestion, improve the traffic ability of the road network. It is the best way to solve traffic problems, and is considered to the development goal of the modern transportation system.

Intelligent transport system consists of the following seven main parts: the advanced traffic management system (Advanced Traffic Management System, ATMS), the advanced vehicle control system (Advanced Vehicle Control System, AVCS); the advanced public transport system(Advanced Public Transportation Systems, APTS); the electronic toll collection system(Electronic Toll Collection, ETC); the Freight Management System (Freight Management System, FMS); the Emergency Rescue System (Emergency Rescue System, ERS); the advanced traffic information service 
system (Advanced Transportation Information Service system, ATIS).

With the development of the intelligent transportation system, the legal relation of different sectors and different types of parties which involved in intelligent transportation become more and more complicated. The intelligent transportation system has change the original allocation of substantial resources, and the extensive use of high technology has change the distribution of rights and obligations among the original traffic relation bodies.

3. Challenges of the Development of Intelligent Transportation for the Transport Law System in China

On July 31, 2012, the third session of the intelligent transport conference opened, it indicated the future developing direction of intelligent transportation in China: pays more attention to serve for public travel and modern logistics, pays more attention to public traffic and slow traffic services ${ }^{[3]}$;pays more attention to security-oriented development and green growth ${ }^{[4]}$,pays more attention to domestic demand.

3.1Demand for Intelligent Transportation Industry Technology Policy Support Legal System

As an emerging technology, intelligent transportation needs the integrated application of monitoring, communication, computer, control, GPS, GIS, and other modern high and new technology to support its normal working, which requires institutional support for the development of emerging technologies from the transport legal system. in the traffic legal system of China, there is not national legal laws and regulations specifically designed for intelligent transportation system, except for the traffic development strategy promulgated by the traffic apartment in 2012, as for the effectiveness level of the strategy, it is not law but national development policy on the intelligent transportation industry; From the local administrative law level, only views on accelerating the construction of the city's intelligent transportation project issued by Nanjing government in 2010, belongs to the special local regulations; the highway law under 10th article of our country provides: "China encourages science and technology research in the highway work aspects, and give award to units and personal that make significantly results on highway science and technology research and application aspects", but there is not related policy that give specific support measures on intelligent transportation industry technology policy, in some degree, this is not helpful to the development of the new technology.

3.2 Demand for intelligent transportation system interconnection security legal system

The aim of intelligent transportation is to improve transportation efficiency by the rational allocation of these transport resources. This requires communication and coordination among departments. An important part of intelligent transportation is relevant departments share the traffic information and achieve interoperability, it not only needs the achievement of interoperability among different modes of the city transportation such as buses, private cars, subways, taxis, but also among railway, road, air, water and sea. Currently, the traffic legal system mainly relies on industry legislation, different transportation modes like highway, railway, aviation, waterway, and shipping, has its own legislation, different transport modes basically carried out their own planning and construction to adapt their needs. Except from some dredging port railway, and dredging port highway and airport highway, the legislation did not take the overall planning and construction of different transportation modes into account, and lack the coherence indevelopment planning and policy and regulation regimes. transportation legal systems lack of effective regulatory regimes on the unfair competition and monopoly, price discrimination that impede interoperability in the 
transportation industry, resulting in connections between the various modes of transport not convenient and making resources wasted.

\subsection{Demand for intelligent transportation} information management legal system

Informatization is an important feature of intelligent transportation which means disclosing information to the driver or the public to build effective links among road, vehicle, driver and the public in order to enhance the working efficiency. Traffic management system and public transportation system in intelligent transportation system both require effective real-time information disclosure. The major cause of traffic jams is in sufficient information disclosure which will waste of transportation resources, management resources and public resources. There are many kinds of the intelligent transportation publishing media, including the Internet, cell phones, TV, in-car terminals, radio, roadside broadcasting, electronic information board and so on. The management agencies of these media are different, so is the audience. How does intelligent transportation system disseminate the information accurately and effectively in a timely manner? Which the format should used? To what extent the information should be disclosed? How to correct the behavior of publishing errors or information missing, delays in publishing information? What are the corresponding legal responsibilities for the illegal behavior? To get answers of these questions should establish a comprehensive information management system. It is not only can help public transportation but also can improve transportation and management efficiency by using comprehensive transportation information management system.

3.4 Demand of establishment of a unified coordination mechanism in the intelligent transportation response system

Intelligent transportation emphasizes harmonization, especially emergency rescue system, which requires the establishment of effective coordination mechanisms between transportation department and other relevant departments. Coordination means traffic control departments can connected with rescue, medical and other professional bodies and make unified action, and make effective treatment of the traffic accident and rescue in the event of emergencies, such as traffic accidents. there are no relevant provisions in our country about emergency guarantee of other transportation modes and communication mechanism between traffic management bodies and other emergency agencies. With the rapid development of modern economic society, impact influencing scope of disaster on city proper function is increasing, it has become one of the important tasks of modern traffic management to establish an emergency response command system, enhanced transportation emergency response capacity and minimize its adverse effects. Therefore the development of intelligent transportation needs the law to make communication mechanism between transport operators and other agencies to achieve timely treatment and loss minimization of traffic accidents.

\section{Suggestion of perfecting the intelligent transportation legal system}

In order to adapt to the development and change of modern transportation industry constantly, play important role of intelligent transportation in improving social productivity, promoting tourism, improving people's lives and enhancing international relations, the legal system can make perfection from the following several aspects:

\subsection{Develop basic legal system and clear industrial policy of intelligent transportation}

To build and improve the resources-saving and environment-friendly intelligent transportation system, intelligent transportation system must have rational industrial policies to guarantee its full development, guarantee their size, layout, structure and technology level meet 
the needs of national economic and social development. Therefore, intelligent transportation basic law should be draw up which should make provisions on the basic system, basic policy and basic principle of intelligent transportation and clear the basic technology policy and technology standard like traffic CCTV monitoring system, license recognition system, national computer network ticket system and passenger service system. To protect the working of key technology of intelligent transportation, the exiting intelligent transportation industrial policy should be legalized and increase the support for the new technology.

\subsection{Interconnection of various modes of transportation}

As a large country with vast territory, China has natural condition of vast size, facing ocean and much developed water system of inland rivers and lakes. The large number of population, cities and industries distribute in wide geographical location; the distribution of resources is not balanced. Therefore, there are various traffic requirements of inter-district, inter-city, urban-rural and city, various modes of transportation have tremendous development and market demand to play a role and the comparative advantage. Base on natural, economic and social conditions, the various modes of transportation should give full play to the role, carry out rational development and network layout in accordance with the principle of combination of functions, complementation of advantages, to form an integrated unity which has rational division of labor, perfect function, coordinate development and close fit ${ }^{[7]}$.

The target of intelligent transportation should be to establish coordinated bodies, make coordinated regulatory framework, foster coordinated talents, apply coordination concept to the planning and design of traffic network and hub, carry out a constantly coordinating work on the integrated transportation production and construction. Unified traffic network and integrated hub coordination development should concern two aspects of problem. One is the integrated traffic hub macro regulation should be reasonable. The aim is to keep the reasonable degrees of freight flow density, avoid traffic jam caused by intense centralization, and avoid traffic and people flow conversion difficulties. On the otherhand, in order to save conversion time, the convergence of various lines in different traffic modes should be close $^{[5]}$.Different traffic modes like highway, metro, railway, airport and waterway should constitute a unified overall take advantage of each other's strengths by coordination.

4.3 Establish traffic information management system

Traffic information technology development should meet the demand of transport service object, and meet the maximum information need of participants ${ }^{[6]}$. The information, such as traffic congestion roads, road speed limits, closed exits when the accident occurred, should make known to public timely. The information management system should include 1) Standardize the static information, which make the public understand the traffic information in a more simple and clear way; 2)Optimize the number and location of information, by publishing dynamic information and disclose the information in correct way which make the user can understand the traffic condition and help them make reasonable decision. 3)Information Forecasting System, which connected with the integration of traffic organization, decomposition and optimize signals in the surrounding area road network ahead of time; 4)sustained information disclose system, which make the public to understand how to get traffic information; 5)correction mechanism for publishing errors, omissions and delay of information;6)provisions on the legal responsibility of violating traffic regulations. 
4.4 Establish communication emergency mechanism between traffic management and other emergency agencies

The intelligent transportation law should rule the government has the responsible to establish traffic management and monitoring agencies and other emergency agencies, including medical institutions, professional rescue agencies etc with intercommunicate joint coordination mechanism. there are some system should be establish:1) Emergency Command System, which undertake traffic management command disposal work and research the traffic emergency preventive work program in different circumstances when major emergencies infrequent events happen; 2) traffic incident reporting system, which can achieve the information submitted as well as with emergency support coordination of joint work between different departments; 3) Coordination linkage mechanism between the command department and other department, which including the information-sharing mechanisms;4)resources guarantees and social mobilization system which including material procurement, transport, storage security system; 5) traffic guidance systems which release real-time traffic guidance information to transfer information efficiency, monitor and warn early preparedness. After establish these system, the original dispersed and isolated State of institutions can form balanced and integration system which will set up the collaboration tie of coordination state and improve traffic emergency guarantees coordination capacity. When the government emergency management responsibility be clear there will be a highly effective, responsive and orderly emergency action system.

\section{Conclusions}

Intelligent transportation plays an increasingly important role in China. But the current traffic laws have not change with the new social relations caused by the emerging field of intelligent transportation. Therefore, there are many measures should be adopt in the intelligent transportation law, such as to clear intelligent transportation industry policy, to make various connectivity transportation regulations, to set up the transportation information management system, and to establish the communication mechanism between traffic management agencies and other emergency agencies.

It is of great significance to conform to the legal requirement of intelligent transportation, and link the traffic legal system of China with the legal system of the world.

This paper is supported by "the Fundamental Research Funds for the Central Universities”.

\section{References}

[1] Yan Xinping, Wu Chaozhong, Yang Zhaosheng: Intelligent transportation systems principle, method and application[M], Wu Han, Wuhan University of technology press, 2006:3-4.

[2] Su Shaoyu:Shallow debate of the development direction of intelligent transportation in our country[J], Heilongjiang traffic science and technology,2011,9,280. [3] Department of transportation:Intelligent traffic transportation industry development strategy(2010-2020),2012.

[4] Li Hong: The ministry of transport: China intelligent transportation development strategy focus on people-oriented[N], International online,http://news.dayoo.com/world/57402/ 201207/31/57402_108832732.htm, 2012-07-31. [5] Luo Renjian: Values and development of the comprehensive transportation system development goals[J], Integrated transport,2011,3,4-8.

[6] Yan Ping/Yang Luping/Yinjing: Emergency traffic guarantee ability connotation and evaluation index system research,[J], Integrated transport, 2011,7,53-55. 
